\title{
Auditory Arguments: The Logic of 'Sound' Arguments
}

\section{LEO GROARKE}

Department of Philosophy

Trent University

Peterborough, ON

leogroarke@trentu.ca

\begin{abstract}
This article discusses "auditory" arguments: arguments in which non-verbal sounds play a central role. It provides examples and explores the use of sounds in argument and argumentation. It argues that auditory arguments are not reducible to verbal arguments but have a similar structure and can be evaluated by extending standard informal logic accounts of good argument. I conclude that an understanding of auditory elements of argument can usefully expand the scope of informal logic and argumentation theory.
\end{abstract}

Résumé: Cet article traite des arguments "auditifs": des arguments dans lesquels des sons non verbaux jouent un rôle central. Il fournit des exemples et explore l'utilisation des sons dans les arguments et l'argumentation. Il soutient que les arguments auditifs ne sont pas réductibles à des arguments verbaux, mais ont une structure similaire et peuvent être évalués en étendant l'application des normes de la logique non formelle d'un bon argument. Je conclus que la compréhension des éléments auditifs d'un argument peut étendre utilement la portée de la logique non formelle et de la théorie de l'argumentation.

Keywords: auditory argument; informal logic; prosody; multimodal argument; visual argument

\section{Introduction}

I understand an argument as an attempt to rationally justify a conclusion (a standpoint) with premises that provide evidence in support of it. So understood, the following remark is a paradigm case of argument.

Example 1: "Karleen may have CHF (Congestive Heart Failure), for she has extreme edema in her legs and ankles." 
This is an argument with one premise ("She has extreme edema in her legs and ankles") and one conclusion ("Karleen may have CHF"). Many would attribute it an additional - implicit - premise which the inference assumes: i.e., "Someone with extreme edema in their legs and ankles may have CHF."

The following example is another case of medical diagnosis:

Example 2: A doctor places a stethoscope on Karleen's chest, listens intently, and concludes: "You may have congestive heart failure."

Is this a situation in which a doctor constructs an argument? It is a situation in which they collect evidence which is used to rationally support a conclusion, but in this case the role of premise is played, not by a sentence, but by the collection of sounds the doctor hears when they listen to Karleen's heart through their stethoscope.

I define an "auditory" ("acoustic" or "sonic") argument as an attempt to provide rational evidence for a conclusion using non-verbal sounds instead of, or (more frequently) in addition to, words. Auditory arguments raise important questions at a time when informal logic and argumentation theory are expanding to incorporate broader accounts of argument. At this point, most of the discussion has focused on "visual" arguments: arguments in which some kind of visual (an illustration, a photograph, a map, a dramatic performance, a video, etc.) expresses a conclusion or provides evidence in favour of one. The relevant literature is chronicled in Kjeldsen 2015, and in three special issues of Argumentation \& Advocacy (see Birdsell \& Groarke 1996; Birdsell \& Groarke 2007; and Godden, Palczewski, \& Groarke 2016).

More recently, an interest in non-verbal elements of argument has expanded to include attempts to understand "multimodal" argument components which may include gestures, sounds, smells and various kinds of experiences (see Groarke 2015; Forceville \& Tseronis 2017). These discussions have included some preliminary accounts of the role of non-verbal sounds in argument. The role of paralinguistic elements of the human voice (pitch, enunciation, accent, volume, etc.) in oral argument has been explored by Kišiček (2015), Van den Hoven \& Kišiček (2017), and Groarke \& Kišiček (2016). Their discussions extend rhetoric's traditional interest in prosody. A

(C) Leo Groarke. Informal Logic, Vol. 38, No. 3 (2018), pp. 312-340. 


\section{Auditory Arguments}

different account of the use of sounds in argument has been developed by Eckstein (2017a, 2017b), who has used the principles of strategic manoeuvring to explain the use of sounds in radio presentations. Pietarinen (2010) and Champagne (2015) have taken a more formal approach to sound, constructing sonic propositional logics in which non-verbal sounds represent propositions and their logical relations.

This essay is intended as a contribution to the discussion these articles have begun. It argues that auditory arguments play an important role in real life argument and that a conscious attempt to recognize them allows us to expand the scope of informal logic and related fields (argumentation theory, critical thinking, etc.) in a way that usefully broadens the range of real-life arguments they can analyze and assess.

\section{Situating auditory arguments}

From a scientific point of view, sounds are what we hear when audible vibrations (waves in the range of 20-20,000 cycles) reach our inner ear and impact our eardrums. As Sterne (2003) emphasizes, this makes sound a human construct which we understand in ways that reflect human cultural and historical perspectives. The distinctions between "a sound," "a noise," "silence," "music," and "normal and abnormal" sounds are, therefore, drawn in different ways at different times and places.

In the world of argument, many arguments which have sound as their subject matter are arguments in the traditional verbal sense. When I say:

Example 3: "The orchestra sounded magnificent: I know because Windsor told me so and he played in an orchestra for many years."

I elaborate an argument about sound (i.e., the sound of a musical performance) but not an argument which can be classified as an "auditory" argument. For this is a case in which the conclusion and the evidence in support of it are both conveyed verbally. In this case the result is a verbal appeal to authority. 
We can usefully contrast this verbal argument with the auditory argument I construct in the following scenario.

Example 4: After listening to a choir, I try to convince you that a singer was flat when she sang the second verse of a folk song by playing a recording of this part of her performance.

In this case, my conclusion is not supported (only) by statements about sounds but by sounds themselves - by the sounds we hear when we listen to a recording.

In an attempt to understand auditory arguments, we can distinguish between "sound objects" and "soundscapes" (see Eckstein 2017b). A sound object is a discrete sound that grasps our attention-fire alarms, sirens, shouts, and the ring of a cowbell are good examples. A soundscape is the broader sonic background in which we are immersed at a particular time and place. A good example of a soundscape is the acoustic backdrop we hear when we are travelling in a bus or walking down a city street.

In auditory arguments key sounds are non-verbal-i.e., sounds that do not have defined meanings in the way that words do. Even in the case of spoken language, such sounds play a key role that conveys meaning in ways that extend beyond that implied by the definitions of the words used. A standard example is the way in which a rise in pitch can turn a statement into a question, and a drop in pitch can make it an objection. As Gilbert 1997 (p.102) notes, the sentence "Fine, fine, you're right, I'm wrong, we'll do it your way." "...can indicate agreement with what has been said if presented flatly... or, if accompanied by an expression of anger, it can mean that the respondent does not agree at all, but is capitulating." In many ways, the non-verbal sounds that accompany spoken language - the speed of one's speech, its rhythm, the emphasis one places on particular words, and the use of sounds like sobs, cries, laughs, and undefined expressions like "blech!" "yuk" and "mmmmmm" - play a role in conveying meaning.

In other cases, the non-verbal sounds that are featured in auditory arguments are not tied to language. Sounds that may be used include the sounds that animals make; natural sounds like the sound of thunder, rain, and the wind; sounds made by machines; musical notes; and sounds that have assigned conventional meanings (alarms, 
beeps, sirens, etc.). As the examples noted in this essay illustrate, non-verbal sounds, sound objects, and soundscapes play a key role in many arguments. The emphasis that traditional accounts of argument have placed on language has, however, meant that their contributions to argument have been largely ignored (one notable exception being the attention rhetoric has paid to prosody and the non-verbal aspects of spoken language).

The following examples outline some typical instances of auditory argument:

Example 5: In medieval times, money lenders had constant problems with counterfeit gold and silver coins. In order to determine which were genuine, they dropped coins on the floor or tapped them, then listened to the sound that resulted. A coin that made the sounds associated with gold or silver was declared to "ring true"; those that did not "rang false" (or "hollow").

Example 6: We conclude that someone is sad because we hear them sobbing.

Example 7: Someone successfully completes a sequence of notes by listening to their pattern and singing the missing notes.

Example 8: An ornithologist listens to the bird call in a video recording of a bird and concludes that it is not an Ivory Bill, but a Pileated Woodpecker.

Example 9: A military official says: "Whenever you hear a siren that sounds like this: [sound s], you are required to enter a bomb shelter. You heard [sound s] yesterday afternoon, so you should have entered a bomb shelter."

In this essay, my aim is a general account of auditory arguments which demonstrates how we can make room for them within informal logic. 


\section{Ways of using arguments}

In attempts to account for real-life arguing, it is helpful to distinguish different ways in which arguments may be used. I will say that arguments are used "as logicians use them" when they are attempts to establish beliefs and standpoints as justified, true, known, or in some other way credible. Arguments aim to achieve this goal by providing evidence in support of their conclusions. A rational ("critical thinking") person weighs such evidence when deciding what they should believe.

Arguments as I have defined them are also used as dialecticians or rhetoricians use arguments: in an attempt to convince someonean interlocutor or an audience - of some point of view. In such situations, they still function as attempts to provide evidence for a conclusion, but they do so in a way that aims to convince other people of some conclusion. This further goal is an important one, for it can significantly affect what counts as successful argument, audiences and the rules that govern our exchange with others restricting what is acceptable in a good argument.

Informal logic is founded on an understanding of arguments as logicians use them, but its interest in public argument has meant that many of the arguments it analyzes are used dialectically or rhetorically. This is why informal logicians often supplement their account of good argument with an account of arguments as dialecticians and rhetoricians understand them, borrowing and sometimes elaborating their accounts of audience and dialectical exchange.

Auditory arguments may also be used in the ways that logicians, dialecticians or rhetoricians use arguments. But the extent to which they are used as arguments (only) in the first sense is especially notable, as in the following examples:

Example 10: A hunter hears a loud noise in the bush and concludes that there is a moose close by.

Example 11: A referee at a football match blows a whistle, and the players conclude that they must stop playing.

Example 12: We hear a voice on our phone and conclude it is our father calling. 


\section{Auditory Arguments}

Examples of this sort reflect the extent to which sound is a medium which is one of our most important sources of evidence about the world around us. Considered from this point of view, we might easily describe humans and other animals as biological machines that rely on hearing as an auditory reasoning device.

Not surprisingly in view of our constant use of auditory arguments in the way that logicians use arguments, they also play an important role in dialectical and rhetorical exchange. Consider the following examples:

Example 13: In the Moor murder trials, one of the key pieces of evidence used to convict Ian Brady and Myra Hindley was a 13-minute tape recording of one of their victims screaming and sobbing.

Example 14: In attempting to convince a prospective buyer to purchase an automobile, a salesperson revs its engine so that they can hear how remarkably smooth and powerful it is. (A television advertisement for the Audi R8 has employed this same strategy, focusing on the sound its engine makes as it accelerates.)

Example 15: In an attempt to prove to a group of musicians that a guitar is terribly out of tune, the member of a band strums a "C" chord.

In cases like these, auditory arguments still function as attempts to provide evidence for a conclusion, but they also function as key instruments which are used in attempts to convince others of some point of view.

\section{Can auditory arguments be reduced to verbal arguments?}

We could analyze and assess auditory arguments by looking for a way to turn them into verbal arguments which can then be analyzed and assessed as verbal arguments. The most obvious way to do so is by describing the sounds that they contain: a process that turns these sounds into words (one might compare attempts to deal with visual arguments by turning them into verbal arguments that describe the

(C) Leo Groarke. Informal Logic, Vol. 38, No. 3 (2018), pp. 312-340. 
visuals in question). This approach is problematic because non-verbal sounds are (like visuals) notoriously difficult to express in words, there being no exact way to translate a non-verbal sound into words.

Consider the following examples of auditory argument, which depend on exhortations of disgust or pleasure; someone's laugh; an unusual noise within a faulty engine; and the sobs and cries of a young girl.

Example 16: Someone in a grocery store picks up a box of biscuits, reads their ingredients to their companion, and declares (concludes) "Blech!" (or "Mmmmmmmm!", or "Arrrgh", or some other nonverbal sound that conveys either disgust or approval).

Example 17: When a video surfaced that recorded a group of Florida teenagers laughing at a man they watched drown, they were roundly criticized by commentators who described their laughing as disgraceful.

Example 18: Mechanics rely on sounds to diagnose problems with an engine. A mechanic who listens to a car engine and hears a strange squeak or twang may conclude that it has defective bearings (or problems with pistons, belts, pulleys, hoses, brakes, suspension, etc.).

Example 19: Groarke \& Kišiček (2016) discuss an example in which a campaign to end child abuse is supported by a recording of an actual 911 call from a child pleading for help: her sobs and cries and trembling voice conveying the pain and horror of child abuse in a better way than her words.

One way to produce exacting verbal equivalents of auditory arguments like these is by relying on ostension, using language as a verbal pointer that identifies the non-verbal sounds in question. Consider the following example.

Example 20: Ornithologists debate the identity of the species of swans on the local river. To settle the issue, one of them records their call, then plays the recording, saying: "They must be Tundra swans, for this is the call they make."

In this case, words are used to convey an auditory argument that depends on the call of the swans. The word this plays the key role, 
invoking the sound in question. This does successfully delineate a set of non-verbal sounds, but not in a way that reduces them to words, for one cannot understand - and analyze and assess - the argument without listening to the sounds in question. In this and other cases, ostension serves as a good way to incorporate sounds into arguments precisely because it does not attempt to turn them into words, verbally pointing them out instead.

The only way to successfully verbalize auditory arguments is by replacing their non-verbal sounds with descriptions of these sounds. In doing so, one does translate sounds into words, but in most cases this comes at a great cost, for such descriptions fail to precisely and completely convey the sound in question. Consider the following auditory arguments for the conclusion that "there must be a cat in the alleyway":

Example 21: "Listen to that: there must be a cat in the alleyway."

Example 22: "I heard a shriek: there must be a cat in the alleyway."

Example 21 includes (by ostension) the sound object which plays the key role in an auditory argument. When we assess the argument we must listen to the sound and decide whether it is plausible to ascribe it to a cat in the alleyway. In Example 22, the sound object is replaced by a description of it as "a shriek." This creates a verbal argument, but an argument which is not equivalent to its auditory counterpart. This is evident if we consider the many questions it raises which are not raised by its auditory counterpart. They include the queries: "Is a shriek a sound associated with a cat?", "Is this description of the sound accurate?", "What specific kind of shriek was it?", "What were its acoustic properties?"

More fundamentally, Examples 21 and 22 propose logically distinct arguments. The argument in Example 22 is an appeal to the testimony of the arguer. It raises the question of whether we should accept their claim and their judgment of the sound in question (as a "shriek," and as the kind of sound a cat makes). In contrast, the argument in Example 21 appeals directly to the sound itself. In this case, we must ask whether what we hear justifies the conclusion:

(C) Leo Groarke. Informal Logic, Vol. 38, No. 3 (2018), pp. 312-340. 
something we can judge for ourselves because we hear it and are not forced to rely on someone else's description of it.

The challenge that arises when we describe sounds in words is one of the reasons why auditory arguments are popular in real life arguing (and increasingly popular as recording technology makes it easier to create and reproduce such sounds). In most circumstances, it is difficult to describe sounds, sound objects, and soundscapes in a precise and detailed way. In such circumstances one can better convey the nature and quality of a set of sounds by presenting the sounds directly, without trying to translate them into words. This is why ornithologists catalogue and collect bird songs, not by describing them, but by collecting recordings of them.

What typically happens in practice is illustrated in the following version of the stethoscope example we began with.

Example 23: Karleen is examined by an intern whose diagnostic skills are being tested by a supervising doctor. The intern places a stethoscope on Karleen's chest, listens to it, and concludes: "You may have congestive heart failure." To evaluate the auditory argument that leads to this diagnosis, the supervising doctor takes the stethoscope, listens to Karleen's chest, and says: "A good diagnosis."

Here the supervising doctor evaluates the intern's auditory reasoning, not by asking her to describe the sounds she heard or the inference she made, but by listening to the sounds herself. An attempt to judge the intern's reasoning by asking her to reduce her reasoning to a verbal equivalent would be judged impractical, imprecise, and peculiar.

\section{Argumentation sounds}

In this essay, I will understand "argumentation" as argument and the broader context of disagreement, dialogue, and persuasion in which it is embedded. In a discussion of the role of sound in argument, it needs to be noted that the broader background in which arguments occur often incorporates sound which in some cases promotes, enhances, discourages, or interferes with arguing. 
Pragma-dialectics (van Eemeren \& Grootendorst 1992, 2004) is a theoretical perspective which understands argumentation as a speech act centered on a "critical discussion" which attempts to resolve a difference of opinion. It outlines ten rules that determine what counts as proper conduct inside such a discussion. Violations of the rules are deemed fallacies. The first of the rules is the "Freedom Rule," which states that the parties to a critical discussion must not prevent each other from advancing standpoints or casting doubt on others' standpoints. In the world of arguing, this is an appropriately foundational principle which makes arguments and critical discussion possible.

When we consider the role of sounds in argument and argumentation, the Freedom Rule is relevant because sounds and soundscapes are often exploited in conscious attempts to violate the rule: i.e., as a way to prevent other arguers from advancing their standpoints. The following (real) situations illustrate ways in which this can be accomplished.

Example 23: A large crowd of protesting students at a local university stamp their feet to prevent a visiting speaker from presenting his arguments on sex and gender, making it impossible to hear him.

Example 24: In North Carolina, Ku Klux Klan members at a protest against immigration are shouted down by counter-protestors who yelled in order to (successfully) prevent them being heard.

In these and similar cases a prospective audience creates a soundscape that makes argumentation impossible, violating the first rule of Pragma-dialectics.

In other circumstances, critical discussions employ sounds in the opposite way, to ensure that arguers have the opportunity to present their standpoints and criticize those of others. In a formal debate, a bell or buzzer may regulate the arguing process, ending one interlocutor's comments in order to allow an opponent to present an opposing point of view. Here again, the role of non-verbal sounds needs to be considered when applying the Freedom Rule and the 
rules of critical discussion, which in this way regulate sounds as well as words within a case of argumentation.

Sounds are a key element of argumentation in another way when they are used as vehicles of persuasion. Consider an interpersonal example:

Example 26: My spouse is more prone to agree with me when she is in a good mood. She loves classical music, so I play her a new recording of the first movement of Beethoven's $7^{\text {th }}$ symphony before I argue that we should buy a new automobile.

In this case, a musical performance sets the stage for argument. It is notable because it is not a neutral background but is used in an attempt to influence the audience to whom my arguments are directed. In many cases of public argument - at political rallies, in advertisements, in documentary film - music or other sounds are used in a similar way.

Two further examples can illustrate the significance of sounds in argumentation when sound objects are used as "auditory flags" which are designed to attract the attention of an audience:

Example 27: A popular up-tempo melody introduces an advertisement, not as a component of an argument it forwards, but as a way to secure our attention. An argument is elaborated in the ad that follows.

Example 28: A speaker claps their hands three times. An audience stops talking and listens; the speaker then elaborates an argument.

Discussions of visual argument have noted a similar use of images, which are often used as "visual flags" which direct us to an argument (see Groarke 1996). Visual and auditory flags play an important role in broader contexts of argumentation because an arguer cannot convince an audience of a conclusion unless they first secure their attention, something that is often difficult in public argument, where audiences are inundated with arguments they learn to ignore. 


\section{Sounds as "inference activators"}

In many cases, sound objects that arguers use as auditory flags also play a role within the argument they aim to attract attention to. The following scenario provides an example of this sort

Example 29: A radio commentary begins with the sounds of a very noisy political demonstration which catches our attention. At the same time, it supports the verbal claim that a very large and unruly demonstration is taking place in front of the Palais de Justice.

In this and other cases, one might describe sounds that lead to auditory reasoning as "inference activators" which provide information (data) in a way that aims to trigger particular arguments and conclusions.

A very simple example of an inference activator is a cowbell. A farmer ties it around a cow's neck as a way to prompt auditory inferences about the cow's location (close, far, in the Northern pasture, the neighbour's field, and so on), as is done in the following example.

Example 30: We are looking for our favourite cow, Sherry. We hear her cowbell over the hill and conclude that she is in the southern pasture.

In Switzerland and other places where cowbells are used, bells with different acoustic properties are tied to different cows so that a farmer can infer the whereabouts of the different cows they own. These bells are "intentional" inference activators which are purposefully designed to activate auditory inferences.

Intentional inference activators are invaluable tools in our day to day reasoning, playing a key role in social interactions, where their meaning is often determined by conventions we all assume. School bells, ambulance sirens, buzzers in a game show, and whistles at a volleyball game are, for example, used to activate particular inferences in those who hear them. In more subtle ways, background noises in a movie or a video game may be used to similar effect (when we hear a minor key in a Hollywood movie, we know that something unfortunate is going to happen). 
In other circumstances, auditory inference activators are unintentional activators, triggering arguments and conclusions which are not specifically intended by those who make or arrange the sound. In the following circumstances, sounds operate in this way:

Example 31: We hear the screech of tires and then the crunch that accompanies one automobile hitting another. We conclude that someone may be hurt and rush to see if we can help.

Example 32: We walk into a bar during the Olympic Games and come across a party singing Ee Mungu Nguvu Yetu (the national anthem of Kenya). Someone points to them and tells us: "They must be celebrating the gold medals in the five and ten thousand metre races earlier today."

The central role that auditory inference activators play in real life reasoning is evident in the way that sounds, soundscapes and sound objects constantly initiate arguments and conclusions that inform our thoughts and actions. Because sophisticated listeners have a superior ability to discriminate between different sounds (musical notes, mechanical noises, natural sounds, voices, etc.), they are especially adept at the auditory reasoning that results, but everyone whose hearing functions properly perpetually uses auditory reasoning in their attempt to understand the world around them.

\section{Analyzing auditory arguments}

The difference between sounds and descriptions of sounds makes the distinction between auditory and verbal arguments a deep one, but not in a way that eliminates the fundamental structure that they share. In both cases, the essential components of an argument are premises (evidence), an inference, and a conclusion.

In view of this shared structure, we can analyze auditory arguments by depicting them in ways that use the diagramming techniques used to depict the structure of verbal arguments. If we let $\boldsymbol{k}=$ "She is suffering from extreme edema in her legs and ankles." and $\boldsymbol{c}=$ "Karleen may have CHF." then we would normally diagram the verbal argument that is Example 1 as follows. 


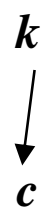

In the present context, the important point is that the same diagram depicts the structure of the auditory argument that is Example 2, where $\boldsymbol{k}=$ the sound the doctor hears when she listens to Karleen's chest through her stethoscope; and $c=$ "She may have CHF."

In both these cases, the arguments in question may be understood as arguments with implicit premises. In Example 1, the implicit premise $([i])$ asserts that someone suffering from edema in her legs and ankles may have CHF. In Example 2 [i] asserts that someone whose chest is characterized by the Sound Objects $\mathbf{c}$ [the sound objects the doctor hears through her stethoscope] may have CHF. In both cases, we can include [i] in our diagram by depicting the argument as:

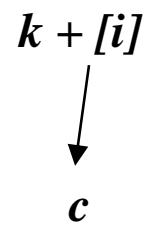

where $[\boldsymbol{i}]$ is the statement that "If $\boldsymbol{k}$, then $\boldsymbol{c}$." As is standardly the case in argument diagrams for verbal arguments, the plus sign (+) in the diagram indicates that the explicit and implicit premise are "linked"-i.e. work together as one set of grounds for the conclusion, providing evidence when they are combined.

The following example illustrates the way in which linked auditory premises can be the basis of an auditory argument:

Example 33: Karleen is examined by an intern who places a stethoscope on her chest, listens to it, and wonders whether he hears sounds that might be a sign of CHF. To check, he listens to a recording of the heart sounds that accompany CHF and compares the recording to the sound objects he hears through his stethoscope. Satisfied that the key sound objects are similar, he concludes that "You may have congestive heart failure." 
In this case, the intern's argument contains two different auditory premises which are linked. The argument that results is:

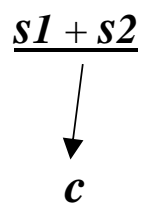

where $\boldsymbol{s} \mathbf{l}=$ the key sound objects the intern hears when he listens to Karleen's heart; and $\boldsymbol{s} \mathbf{2}=$ the key sound objects he hears when he listens to a recording of the sounds that accompany congestive heart failure.

In auditory arguments, as in verbal arguments, "convergent" premises provide independent evidence for the same conclusion, as in the following example.

Example 34: Karleen goes for a physical exam with a persistent cough. The doctor places a stethoscope on her chest and listens to her heart. She then asks Karleen to breathe deeply and listens to her cough. Because each sound is a symptom of $\mathrm{CHF}$, she concludes that Karleen may have CHF.

In this case, the two distinct sounds heard by the doctor provide independent evidence for the conclusion that Karleen may have CHF. We can depict the structure of their reasoning as:

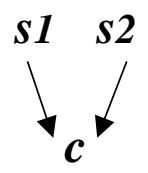

where $\boldsymbol{s} \mathbf{1}=$ the sound the doctor hears when she listens to Karleen's chest; $\boldsymbol{s} \mathbf{2}=$ the sound she hears when she listens to Karleen breathe and cough; and $\boldsymbol{c}=$ "Karleen may have CHF."

In real-life argumentation, auditory arguments are often featured in complex chains of reasoning which employ many auditory and non-auditory premises, layered inferences, and a main conclusion backed by intermediate conclusions. In the following example, an argument combines auditory, verbal, and visual premises in support of the conclusion that Karleen has CHF:

(C) Leo Groarke. Informal Logic, Vol. 38, No. 3 (2018), pp. 312-340. 
Example 35: Doctors diagnosing Karleen's condition appeal to a theory about CHF which incorporates an account of its symptoms. In determining whether Karleen has CHF, they consider this theory $(t)$, the sounds they hear when they listen to Karleen's heart $(\boldsymbol{h})$; her report that she suffers from fatigue $(\boldsymbol{f})$; the sound of her breathing $(\boldsymbol{b})$, and an echocardiogram $(\boldsymbol{e})$ which provides them with an image of her heart. They conclude that Karleen may have CHF $(\boldsymbol{c})$ and $(\boldsymbol{d})$ that she should be treated with a drug known for its ability to alleviate the symptoms of CHF $(\boldsymbol{a})$.

Here we have an extended argument that can be diagrammed as follows.

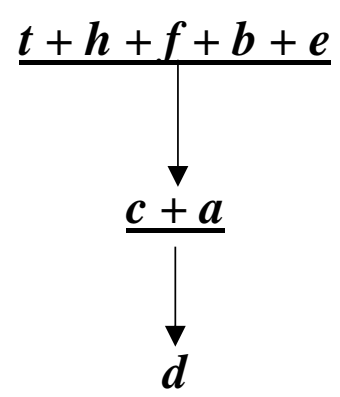

Examples like this approximate the way that medical diagnosis operates in real life circumstances, where observations of many different sorts (visual, verbal, auditory) combine with scientific and medical theories in support of a tentative conclusion about a patient's health, ailments, and possible treatment.

As these examples show, we can analyze auditory arguments by applying well established diagramming methods. What makes this possible is a shared logical structure which consists of premises, inferences, and conclusions. In both cases, arguments may contain implicit premises, linked or convergent premises, complex combinations of premises, many layers of inference, and multiple conclusions that are supported by different kinds of premises (verbal, visual, auditory). In both cases, diagramming depicts an argument's structure in a way that prepares it for assessment. 


\section{Criteria for good argument}

In the case of verbal reasoning, good arguments must be "wellformed": i.e., constructed in a way that makes them intelligible attempts to provide evidence for a conclusion. To achieve this goal, a well-formed verbal argument (formal or informal) must make syntactic and semantic sense. When arguments are composed of words, arguments may fail to do so for many reasons: because the words and sentences they contain are vague and unclear, because they are meaningless in some way, or because they are ungrammatical or for some other reason impossible to understand.

Like good verbal arguments, good auditory arguments must also be well-formed. Insofar as they depend on words, they can fail to be so in the ways that verbal arguments fail to do so. Other reasons why auditory arguments may not be well-formed are more directly tied to the non-verbal sounds, sound objects and soundscapes that they incorporate. In such cases, such sounds may be faint and inaudible; obscured by competing noises; corrupted by problems of transmission; distorted by poor recording, or in some other way unintelligible. Like words, a sound can be ambiguous because it can be interpreted in different ways (as the sound of the wind or a shout).

Well-formed arguments are intelligible attempts to support a conclusion with evidence. In the case of auditory arguments, they do so in a way that employs non-verbal sounds. In both cases, being wellformed is a prerequisite for good argument, but only a prerequisite. When arguments are well-formed we need to answer the question of whether they are good arguments by considering whether they satisfy the normal criteria for good argument. Here I will summarize these criteria by deeming a good argument (verbal, visual or auditory) to be an argument which has acceptable (true, plausible, etc.) premises and a conclusion that follows from them (plausibly, probably, or with certainty). In judging whether these criteria are met, we can assess auditory arguments in the ways that verbal arguments are assessed: by looking for standard fallacies (straw man, post hoc, ad hominem, etc.); by asking the critical questions associated with argument schemes (argument by analogy, causal reasoning, etc.); by applying standard accounts of deductive and inductive validity; and so on.

(C) Leo Groarke. Informal Logic, Vol. 38, No. 3 (2018), pp. 312-340. 


\section{Premise acceptability}

In classical logic, the ideal argument is an argument with true premises and a (deductively) valid conclusion (traditionally classifiedunfortunately in the present context — as a "sound" argument).

In attempts to apply logic to real-life arguments, the first of these requirements - the requirement that premises be true-has given way to the broader notion that a good argument must have premises that are "acceptable." Here it will suffice to say that this is a move designed to accommodate real-life contexts in which a truth requirement is difficult to apply: because premises which are uncertain may be an acceptable basis for argument in situations in which truth and probable truth are difficult to judge; because some kinds of dialogue (eristic dialogue, bargaining, etc.) expressly permit premises which are not true; and because an appeal to truth raises complex philosophical issues, especially in moral, social, political, and aesthetic contexts.

In the case of verbal premises, a premise may be acceptable for different reasons: because it reliably represents the world; because it is morally, politically or aesthetically appropriate; because it corresponds to widely held beliefs; because it is in keeping with established conventions; or for other reasons that might be enumerated. The question of whether standard notions of premise acceptability can be applied to the premises of auditory arguments can, in view of this, be put as the question of whether they can be usefully judged to be acceptable (and unacceptable) in these and similar ways. We can see that this is so by considering some common forms of premise acceptability.

\section{a. Acceptable by reliably representing the world.}

In many cases of auditory argument, sounds are an acceptable basis for a conclusion about the world because we have good reasons for believing that they correctly represent it (or no reason to doubt that this is so). In the course of our daily lives, the auditory arguments that we depend on to decide what is going on around us typically have premises of this sort.

In contrast, some auditory arguments use auditory evidence that is unacceptable because we have good reason to believe that it is 
unreliable. Sounds heard during an auditory hallucination (a paracusia) are an obvious example, and there are many other, less extreme, cases in which sounds are produced in ways that raise questions about their reliability. Consider the following situation:

Example 36: A music critic plays a recording of a performance of the first movement of Mozart's Symphony No. 40 to prove that it was an inferior performance.

In this example, the recording the critic plays functions as an auditory premise which is acceptable if and only if it accurately reproduces the performance: something it may fail to do for many reasons: because it is a recording of a different performance; because it is a poor recording; because there are technical problems with the playing of the recording; because the recording has been tampered with; and so on.

When a stethoscope is working properly, the sounds one hears when one listens through it (in Example 2 and its many variants) function as acceptable auditory premises that allow an arguer to draw reasonable conclusions. When a stethoscope misfunctions or for some reason fails to transmit sounds accurately (as sometimes occurs), they are unacceptable evidence in an auditory argument.

In human interactions, the non-verbal sounds we make (sighs, laughs, sobs, etc.) are acceptable auditory evidence for a conclusion about someone's mental state when they are a "true" expression of their feelings and unacceptable evidence when they are fabricated for other reasons. The latter occurs when someone sobs and cries, not because they are genuinely upset, but in order to garner sympathy. The sobbing which is used as evidence for a conclusion in Example 6 may, in view of this, be an acceptable or unacceptable premise for an argument to the conclusion that someone is sad (and the further conclusion that we should respond accordingly). In the case of the Moor murders (Example 13), the screams and crying of the murder victims functioned as reliable auditory evidence because there was no reason to doubt its veracity.

b. Acceptable by being morally, politically, or aesthetically appropriate. 
In many situations, non-verbal sounds can be judged from a moral, political or aesthetic point of view because they express moral, political, or aesthetic judgments. Examples are the use of applause (or, more formally, a twenty-one gun salute or Charpentier's Marche de triomphe) to express approval, and the use of hisses, jeers or boos to express disapproval.

When used as evidence in auditory reasoning, such sounds may be acceptable or unacceptable on moral or political grounds because it is morally or politically clear that they are associated with a situation that warrants (or does not warrant) such treatment. In hindsight, the wild applause for Hitler which is featured in Leni Riefenstahl's propaganda film, Triumph of the Will, can be recognized as radically inappropriate, but at the time served as evidence that he was a great leader who should be followed and admired. In hindsight, this can now be seen as unacceptable evidence for this conclusion.

The role of sounds in these kinds of contexts means that many moral principles may apply to sounds. The Florida teenagers who laughed at a man as they watched him drown (Example 17) were roundly criticized on the basis of an argument which might be summarized as follows:

Premise 1: The teenagers laughed like this [sound $l$ ].

Premise 2: Laughing like [sound $l$ ] is a morally repugnant to make fun of someone suffering a terrible tragedy.

Conclusion: The teenagers behaved in a morally repugnant way.

In this case, Premise 1 is acceptable because there is no reason to doubt the reliability of the video of the teenagers (which they made themselves) and Premise 2 is acceptable because it is a plausible moral principle that applies to laughter.

The role of aesthetic judgments in the evaluation of sounds is particularly clear in the case of music (as in Example 15 and Example 36). A musical audition is designed as an inference activator which allows listeners to draw conclusions about someone's ability to sing or play a musical instrument. The sounds that they produce are used as evidence in reasoning which invokes principles that class 
particular kinds of sound as beautiful, unique, impressive, inferior, deficient, and so on.

\section{c. Acceptable by corresponding to widely held beliefs.}

In real life argumentation, the burden of proof usually falls on those who argue against received points of view. This makes other points of view unacceptable starting points for argument. The same principle can be applied in the case of auditory arguments, which must be founded on auditory premises which are in keeping with widely held beliefs (that a sound object is, for example, best understood or evaluated in a particular way). When a sound produced by dropping a coin on a stone is (as in Example 5) generally recognized as a reliable indication of its content and is generally recognized as the sound of a gold coin, these are acceptable auditory premises in support of the conclusion that a coin which makes a certain sound is genuine.

\section{d. Acceptable by being appropriate by convention.}

When we hear a referee blow a whistle in a football match, this is acceptable evidence for the conclusion that we should stop playing (Example 11). When we hear the same whistle sound produced by someone blowing a whistle in the stands, it is an unacceptable basis for this conclusion. This is because the conventions that define the game dictate that a certain sound is an acceptable basis for a conclusion when it is produced in a particular way (in this case, by a referee's blowing of a whistle). Sirens, the striking of a bell, a gong or a gavel, the use of a siren or a bugle, etc., all have proper uses defined by the conventions that regulate their use - conventions that may determine that a particular sound object or a statement about it is or is not an acceptable auditory premise.

\section{Valid and invalid arguments}

I do not propose the above principles of premise acceptability as an exhaustive or systematic list of everything that can make premises acceptable and unacceptable. My aim is more modest: to show that there are well-established ways in which non-verbal sounds and sentences that contain them can, like verbal claims, be deemed 
acceptable or unacceptable. This is enough to show that the first criterion for good argument - acceptable premises - can be applied to auditory arguments.

The second criterion for good argument requires that an argument's conclusion follow from its premises. For the sake of simplicity I will call arguments that satisfy this criterion "valid" leaving open the possibility that such arguments are valid deductively, inductively, conductively, or in some other way. In the case of auditory arguments, this raises the question whether and how they can be assessed as valid and invalid.

In most cases of auditory argument, it is not difficult to apply standard requirements for validity. The argument:

Example 37: [Mechanic to customer:] "If you hear this [plays a recording of sound $\boldsymbol{p}$ ], it is a piston slap and we need to realign the piston rods. [Mechanic and customer listen to the customer's car engine and hear:] [Sound $\boldsymbol{p}$.] [Mechanic to customer:] We will have to realign the piston rods.

is a paradigm example of a deductively valid argument. In other cases, auditory arguments are inductive. In the argument:

Example 38: A homeowner listens to starlings in their backyard over the course of a year and concludes that some sound object $[\boldsymbol{d}]$ is the call of a distressed starling.

An arguer generalizes from particular instances of a sound object to a generalization. Assuming a limited scope of observation, such an argument might be classified as invalid. In that case it is a case of "hasty generalization," a categorization which illustrates the point that auditory reasoning may be fallacious in standard ways.

As in the case of verbal arguments, the valid inferences that good auditory arguments depend on may be plausible, probable, inductively strong, deductively valid (in a traditional or a defeasible way), or convincing in some other way. Like verbal inferences, they can be strengthened by adding more evidence in support of a proposed conclusion. In Example 2, the sound of Karleen's heart provides plausible evidence for the conclusion that she may have CHF, but the inference is not as strong as that proposed in Example 35, where the same evidence is supplemented with other kinds of evidence. 
When we assess the validity of verbal arguments, our assessments sometimes turn on the question of whether an argument is an instance of a particular argumentation scheme or occurs in a particular kind of dialogue. In the auditory case, arguers frequently employ instances of the scheme "argument by sign" (as we do when we take a cry to be a sign that someone is in pain or the ring of a doorbell to be a sign that someone is at our front door). The norms and purposes that are associated with different kinds of verbal dialogue (see Walton 2008) are also tied to many instances of auditory reasoning, which may serve different purposes and require that arguers abide by the different norms associated with scientific inquiry, negotiation, rhetorical success, and so on.

The question of whether there are auditory variants of all the criteria used to judge the validity or invalidity of verbal arguments merits further study. So too does the question whether there are any unique schemes of argument that are intrinsically auditory. It is in this regard worth asking whether we can claim of auditory arguments what Dove $(2013,2016)$ claims of visual arguments: i.e., that there is at least one important scheme ("argument from fit") which is inherently non-verbal.

\section{Kišiček and Eckstein}

In this essay I have tried to show how informal logic can expand its scope to accommodate auditory arguments. One might reasonably respond by asking how my account relates to recent studies of auditory argument. Of special note is the work of Kišiček (found in Kišiček 2015; Hoven \& Kišiček 2017; and Groarke \& Kišiček 2016) and Eckstein (2017a; 2017b).

In her work, Kišiček emphasizes the prosodic elements of spoken language. As she and her co-authors show in numerous examples, these kinds of elements - the way a voice uses pitch, accent, stress, volume, rhythm (or lack of it), etc. - can play a crucial role in presenting oral argument, where ways of speaking and particular kinds of voices are used to communicate important messages (as a soft feminine voice may be used to convey compassion, a strong male voice may be used to convey authority, and an Oxford accent may be used to convey sophistication or pretense).

Like Kišiček, Eckstein adopts a rhetorical approach to argument, but his work focuses on non-verbal sounds that occur outside of

(C) Leo Groarke. Informal Logic, Vol. 38, No. 3 (2018), pp. 312-340. 
prosody (in, for example, the musical background to a radio presentation). In his account of their role in argumentation he emphasizes the extent to which sounds are embodied, immediate, and immersive, and focuses on the ways in which they can provoke visceral memories, convey urgency and direct arguers. In judging the reasonableness of auditory argumentation, he considers the force and speed of sound and its ability to "mask" someone's position.

In many ways, the work of Kišiček and Eckstein can be described as research on the semiotics of sound. It is especially important because our interpretations of sound - and the ways that we rely on it in argumentation - are frequently unconscious. In the normal course of our lives, we hear sounds and infer conclusions, but constantly do so without explicitly recognizing the auditory arguments this implies (by unconsciously responding to sounds qua inference activators). As a result, we fail to submit such arguments to analysis and evaluation.

To take one example, the soundtrack in an advertisement may be purposefully constructed to convince us that it is exciting to drive a particular automobile. It typically does so by a kind of equivocation which encourages us to equate (and confuse) an exciting sound with the driving experience which happens to accompany it. This is an instance of fallacious argument which easily goes unrecognized because we do not treat it as an argument which needs to be analyzed and assessed. By increasing our awareness of the use of sound within argumentation, the accounts of acoustic meaning we find in authors like Kišiček and Eckstein can (especially if they can be combined in a general account of sound) prepare the way for a broader appreciation of auditory argumentation and the ways in which it should be interpreted and assessed.

\section{Conclusion}

In this essay, I have tried to show that non-verbal sounds play a significant role in reasoning, argument, and argumentation more broadly conceived. In the process I have tried to provide a series of examples that illustrate some of these roles in practice. In many of these cases, sounds can be described as auditory inference activators which elicit arguments (in some cases intentionally, in some cases

(C) Leo Groarke. Informal Logic, Vol. 38, No. 3 (2018), pp. 312-340. 
not). The sounds that play a role in auditory arguments include the sound of the human voice, mechanical sounds, music, the sounds that animals and nature make, and the sound objects and soundscapes that surround us in our daily lives.

For reasons I have elaborated, auditory arguments cannot be reduced to verbal arguments that describe sounds. The latter are derivative, approximate, and cannot reproduce sounds in an exact and precise manner. Though auditory arguments are in this way distinct from verbal arguments, they still have many of the characteristics of verbal (and other kinds of) argument. Most significantly, they share a similar premise and conclusion structure can be diagrammed in standard ways and can be assessed using criteria similar to those we routinely apply in assessing verbal arguments (most notably, premise acceptability and argument validity).

The proposed account of auditory argument can significantly expand the scope of informal logic and the range of arguments it is able to encompass. In dealing with complex arguments, it allows us to deal with the auditory components of multimodal arguments which support conclusions with many kinds of evidence: verbal, auditory, visual, and so on. The most important reason for including auditory arguments in the corpus we consider is because this is a way to subject them to critical assessment.

I will conclude this essay by noting one shortcoming: that it is a silent written essay which is in this sense soundless. This is unavoidable in the circumstances but unfortunate given that we can best appreciate the significance of sounds and auditory arguments by actively listening to them. With that in mind, it is worth noting that the limits of an essay like the present one will be alleviated by the development of digital technologies which make it easier and easier to create, transmit, and reproduce sound. As this development continues, there is no reason to doubt that future theories of argument will fully embrace auditory arguments and its auditory elements. 
Acknowledgements: I am indebted to a number of people who have helped me clarify my thinking about auditory arguments. First and foremost, I want to thank the two referees who provided comments on this paper-comments that forced me to clarify some important conceptual distinctions. I am also indebted to argumentation theorists whose work convinced me that we need to better account for the use of non-verbal sounds in argumentation - most notably Gabrijela Kišiček, Paul Van den Hoven and, more recently, Justin Eckstein.

\section{References}

Birdsell, David and Leo Groarke (eds). 1996. Special issue on visual argument. Argumentation and Advocacy 33(1,2).

Birdsell, David \& Leo Groarke (eds). 2007. Special issue on visual argument. Argumentation and Advocacy 43(3,4).

Champagne, Marc. 2015. Sound reasoning: Prospects and challenges of current acoustic logics. Logica Universalis 9(3): 331-343.

Donahue, Michelle. 2017. Possible ivory-billed woodpecker footage breathes life into extinction debate. Audobon. URL accessed 14 August 2017:http://www.audubon.org/news/possible-ivory-billed-woodpecker-footage-breathes-life-extinction-debate>.

Dove, Ian. J. 2012. Image, evidence, argument. In Topical themes in argumentation theory. eds. van Eemeren, F.H. and B. Garssen, 223-238 Amsterdam: Springer-Verlag.

Dove, Ian J. 2013 Visual arguments and meta-arguments. In Virtues of argumentation: Proceedings of the tenth OSSA conference. eds. Mohammed, Dima and Marcin Lewiński, Windsor: Ontario Society for the Study of Argumentation. http://scholar.uwindsor.ca/ossaarchive/OSSA10/papersandcommentaries/38.

Dove, Ian J. 2016. Visual scheming: Assessing visual arguments. Argumentation and Advocacy 52 (1): 254-264. 
Eckstein, Justin. 2017a. Radiolab's sound strategic maneuvers, Argumentation 31(4):663-680.

Eckstein, Justin. 2017b. Sound Arguments. Argumentation and Advocacy 53(1):163-180.

https://doi.org/10.1080/00028533.2017.1337328.

van Eemeren, F. H. and R. Grootendorst. 1992. Argumentation, communication, and fallacies: A Pragma-dialectical perspective. Hillsdale, NJ: Lawrence Erlbaum Associates.

van Eemeren, F.H. \& Grootendorst, R. 2004. A systematic theory of argumentation: The pragma-dialectical approach. Cambridge: Cambridge University Press.

Fahenstock, J. 2011. Rhetorical style: The uses of language in persuasion. New York: Oxford University Press.

Forceville, Charles and Tseronis, Assimakis. 2017. Multimodal argumentation \& rhetoric in media genres. Amsterdam: John Benjamins (Argumentation in Context).

Gilbert, Michael A. 1997. Coalescent argumentation. Mahwah, NJ: Lawrence Erlbaum Associates.

Godden, David, Catherine H. Palczewski, and Leo Groarke (eds.). 2016. Twenty years of visual argument. Argumentation and Advocacy 52(4).

Groarke, Leo. 1996. Logic, art and argument. Informal Logic 18 (2\&3): 116-131.

Groarke, Leo. 2015. Going multimodal: What is a mode of arguing and why does it matter? Argumentation 29 (2): 133-155.

Groarke, Leo \& Kišiček, Gabrijela. 2016. Compassion, Authority and Baby Talk: Prosody and Objectivity. In Argumentation, objectivity and bias: Proceedings of the Ontario Society for the Study of Argumentation conference, Vol. 11, eds. Benacquista, L. and \& Bondy, P. Windsor: University of Windsor.

http://scholar.uwindsor.ca/cgi/viewcontent.cgi?article=2192\&context=ossaarchive

(C) Leo Groarke. Informal Logic, Vol. 38, No. 3 (2018), pp. 312-340. 
Hickson, M., Stacks, D. and Moore, N. 2004. Nonverbal communicationStudies and applications. Los Angeles: Roxbury Publishing Company.

Hoven, Van den Paul and Kišiček, Gabrijela. 2017. Processing multimodal legal discourse; the case of Stanley 'Tookie' Williams. Studies on Argumentation \& Legal Philosophy Vol 2. Quaderni Della Facolta Di Giurisprudenze Vol. 28 Trento: Universita degli Studi di Trento.

Knapp, M. L. and Hall, J. 2013. Nonverbal communication in human interaction. $5^{\text {th }}$ ed. New York: Thomas Learning Inc.

Kišiček, Gabrijela. 2015. The role of paralinguistic features in the analysis of multimodal argumentation. In Proceedings of the 8th international conference on argumentation, eds. Garssen, B, Godden, D, Henkemans, Mitchell, F. Amsterdam: International Society for the Study of Argumentation (ISSA).

Kjeldsen, Jens. 2015. The study of visual and multimodal argumentation. Argumentation 29(2): 115-132.

Pietarinen, A.V. 2010. Is non-visual diagrammatic logic possible? In Studies in diagrammatology and diagram praxis, eds. Pombo, O. and Gerner, A., 73-81, London: College Publications.

Sterne, Jonathan. 2003. The Audible Past: Cultural Origins of Sound Reproduction. Durham: Duke University Press.

Walton, Douglas N. 2007. Dialog Theory for Critical Argumentation. Amsterdam: John Benjamins Publishing Company.

Walton, Douglas, Christopher Reed, Fabrizio Macagno. 2008 Argumenta tion Schemes. Cambridge: Cambridge University Press 